\title{
EHMTI-0156. Quantitative sensory testing in patients with headache attributed by idiopathic intracranial hypertension - a case-control study
}

\author{
H Yri ${ }^{*}$, S Munksgaard, L Bendtsen, R Jensen \\ From 4th European Headache and Migraine Trust International Congress: EHMTIC 2014 \\ Copenhagen, Denmark. 18-21 September 2014
}

\section{Background}

In patients with idiopathic intracranial hypertension (IIH) headache often persist as a disabling symptom even after intracranial pressure (ICP) has normalized. Yet very little is known about the mechanisms of chronification.

\section{Aim}

To explore pain perception in patients with IIH in a controlled design at time of diagnosis and after 3 months of treatment.

\section{Materials and methods}

We explored pain perception in patients with newly diagnosed IIH by Quantitative Sensory Testing (QST) measuring cephalic and extra-cephalic supra-threshold pain ratings and pain thresholds for pressure and electrical stimulation. QST was performed at diagnosis and after one and three months. ICP was measured at baseline and at the 3-month follow-up. QST measurements from sex-matched controls were used for comparisons. Headache was assessed by monthly standardized interviews and headache diaries.

\section{Results}

At baseline IIH patients $(\mathrm{n}=28)$ showed no consistent abnormalities in pain sensitivity or thresholds $(\mathrm{p}>0.09$ for all comparisons to healthy controls $(\mathrm{n}=28)$. Although headache improved markedly and ICP normalized in $52 \%$, there was no consistent change in pain sensitivity from baseline to follow-up ( $p>0.09$ for all variables). Patients with (54\%) and without persistent chronic headache (46\%) 3 months after diagnosis showed no different pain perception either at baseline or at the 3-month follow-up.

\section{Conclusions}

Although headache persisted as a chronic symptom in half of the patients we found no evidence of increased central pain sensitivity suggesting that headache chronification in IIH is caused by mechanisms other than central sensitization.

Published: 18 September 2014

doi:10.1186/1129-2377-15-S1-C65

Cite this article as: Yri et al.: EHMTI-0156. Quantitative sensory testing in patients with headache attributed by idiopathic intracranial

hypertension - a case-control study. The Journal of Headache and Pain 2014 15(Suppl 1):C65.
Submit your manuscript to a SpringerOpen ${ }^{\odot}$ journal and benefit from:

- Convenient online submission

- Rigorous peer review

- Immediate publication on acceptance

- Open access: articles freely available online

- High visibility within the field

- Retaining the copyright to your article 